parently perfectly healthy, but on gently passing a probe along its interior I found a place where the wall was very thin, and on opening it up found an ulcer. An appendix may be found thickened and undoubtedly inflamed; and there may be adhesions, dense or otherwise; or it may not be possible to find the appendix, but breaking down the adhesions appears to promote a cure. The appendix may lie in a localised abscess, and in such cases a minute perforation can generally be discovered, or the appendix may be gangrenous in a cavity containing pus.

Passing by, then, the cases where operation is clearly indicated, we approach the problem of operation or not during an acute attack. Up to the present time my opinion has been against operation at this time, and I have not yet changed it but some recent cases of operation have given me cause fo thought as to whether it wo:? not be wiser to operate in such cases if the operation were done early. There was a girl in the infirmary some months ago suffering from acute appendicitis. She recovered somewhat, but not entirely; her temperature did not become normal, or, if it did, it did not remain normal, After some weeks of this slight pyrexia I operated and found no trace of pus, as I expected, but any amount of adhesions; these I broke down; but could not find the appendix. She recovered rapidly and perfectly after the operation. Would it not have been better to have operated during the acute attack in this case, when the adhesions would have been soft, easily broken down, and the appendix probably found? Now I do not feel sure that she may not have another attack at any time.

In the early part of last year I saw a young lady suffering from an ordinary attack of acute appendicitis. Instead o getting better she developed an abscess over the site of the appendix; this I opened widely. searched its interior, but could not find the appendix. I was careful not to break down any adhesions, as I did not want to infect the general peritoneal cavity. She made a good and rapid recovery; the wound closed, and she went about as usual. Six months afterwards all the old symptoms came back, and in the course of about a week a large abscess formed; this I opened through the cicatrix, giving exit to several ounces of very fetid pus. I again searched the interior of the cavity as carefully as I could, but could not trace the appendix. She has now again completely recovered, the wound remained open longer than before, but it is now soundly closed. She feels well and as strong as ever, but one can scarcely feel safe about her. Would it not have been better to have operated on her in the early days of the first attack, and removed the appendix?

A boy that I saw with Dr. Elliott and Dr. Foster of Barrow had a fulminating attack. The following are Dr. Foster's notes of the case, and it will be seen that, although he diagnosed appendicitis, there were really no symptoms that called for even a consideration of operation until the day of operation and death.

F. B., aged 12 years. October $5^{\text {th, }}$ rcor. Went out after the hounds without breakfaet; came in at ro A.M., had a cup of tea and a bun. Eating bed sickness al in ther broun 作 in October oth. Vomiting continued, areen liquid, bowels not moved. Tem Den peratura pide of pulso normal; gave soap and water enema; two soft motions, containin pulse normal, gaper an twice still in pain temperature and pulse normal dree, and pulse normal. October sth No sickness gave another enema brought away soft motion with more almouds pain much relieved, slept off and on all day. Vomited again at 7 .M. no pain, no sickness tomerature normal, and pulse 60 . October pain, Pain sekans, tem during night, and sickness in early morning. Saw him at Ir A.M., in great pain temper ture roo. $2^{\circ}$, pulse 85, the frst time there had been any rise. I biked straight in to areed that an operation was the only thing to be done. Ther refused We greed tha lalf an hour to decide, and then they agreed. Dr. Elliott brought gave them hall an hour todecide, and then they agreed. Dr. and at 3.30 P.M. was 160 . The boy survived the operation two hours and and at 3.30 P.M. Was 160 . The boy survived the operation two hours and got beyond 70 till the Sunday that he was operated on. On opening the peritoneal cavity a quantity of thin turbid fluid escaped. On bringing up the appendix from its adhesions an abscess was opened, from which pus welled, quite different in character from the fluid in the general cavity. In the wall of the appendix I found a perforation, and in its cavity an almond kernel.

This was a case of apparently very mild acute appendicitis suddenly becoming fulminating. If the rule had been operate in all cases of appendicitis, the result might have been different.

Some time ago 'I saw a gentleman who had been suffering continued feverishness for months. He complained of pain at the epigastrium, this epigastric pain was of but some weeks standing, before then his pain had been vague both in position and duration. There was a distinct fullness at the epigastrium, so I cut down on it and opened an abscess. He improved somewhat, but very shortly became worse and died. A post-mortem examination showed that the abscess which $I$ opened was only one of several in the liver. The appendix was found bound down by adhesions and full of pus; evidently the appendix was the starting-point of a fatal case of pyaemia.

There are at the present time two young women in the infirmary upon whom $I$ have operated. The condition found in each of these cases makes it extremely probable that a recurrence would have taken place very shortly, and also that the recurrence would very possibly have soon become fulminating. I saw both these cases during the acute attack, and refrained from operating. One of them I saw with Dr. Mann, and I think she escaped very narrowly. I found at the operation that the appendix was in a mass of adhesions, and that the manipulation necessary separated the appendix from the proximal end along a line of circular ulceration; the cavity contained pus, and there was a fan-shaped ulcerating surface at the distal end.

The other patient I saw with Dr. Burlingham of Hawarden. At the operation I opened an abscess, and a faecal concretion escaped. I cut away a mass of adherent material in which was the ragged appendix and several small concretions.

I feel that both these cases ran a very grave risk of becoming fulminating. But as yet I hesitate. I still think if the operation were done after the first forty-eight hours during an acute attack that the mortality would be greater than it is by waiting for an interval.

\section{A Cliniral 象erture}

\section{SOME CASES OF CHRONIC NON- MALIGNANT GASTRIC ULCER.}

Delivered at University College Hospital, January 5th, 1902. BY ARTHUR E. BARKER, F.R.C.S.,

Professor of Surgery at University College and Surgeon to University College Hospital.

Gentlemen,--The last nine cases of non-malignant chronic disease of the stomach and duodenum which you have recently had an opportunity of seeing treated in my wards offer a good opportunity for the study of this affection in several aspects. I take, therefore, this occasion while they are fresh in our minds to draw your attention to them again and to point out some of the matters we may learn from them. Three of them are still here before you.

I cannot do better than review them in the reverse order of their occurrence. This will place before you first the simpler forms of ulceration, or, at least of inflammation of the stomach ; next, the more severe forms of the same associated with sharp bleeding; thirdly, the results of cicatricial contraction due to chronic inflammation of the organ and, lastly, the most dangerous consequence of the latter, namely, perforation of the stomach

You have had an opportunity of seeing that the treatment of these three groups has been quite different, as have also the results.

The group is made up as follows:

Case I.-Chronic ulceration, moderate haematemesis. Convalescing Case II.-Ulceration, obstinate vomiting, but no haematemesis. Convalescing.

Case UI-Ulceration, moderate vomiting, sharp recurrent haematmesis. I performed gastro-enterostomy on this patient since. Recovery perfectly uneventfil.

Case IV.-Ulceration, moderate vomiting, fatal recurrent haematemesis. 
Case v.-Ulceration of duodenum, no vomiting of blood, severe recurrent bleeding by bowel, gastro-enterostomy. Cure.

Case vi.-Ulcer of pylorus, stenosis, gastro-enterostomy. Cure.

Case viI.-Ulcer of stomach, "licur-glass contraction," gastro-enterostoiny. Cure.

Case virr. - Ulcer of stomach, perforation, operation. Recover Twenty-eight days later dearh from pulmonary embolism due to septi thrombosis of inferiur iliac vein from ulceration in the vagina.

Case Ix--Ulcer, pertoration, general peritonitis. Operation. Death from shock and persistence of peritonitis

Cases I and II represent an early and very common form of gastric disease such as you $\mathrm{m} н \mathrm{y}$ often see treated in the outpatient department or the medical wards, rarely in the surgical. But I was asked by private friends to take the patients under my special care, and they are here in my beds. I do not regret this, as it enables me and you to group and contrast these non-malignant cases from their earliest and not very dangerous forms to their most terribly complicated varieties, the consequence of neglect.

\section{Case r.}

A delicate clerk, aged 16. Two years ago he was treated at another hospital for chronic diarrhoea, and four months ago for "gastritis," with frequent vomiting of thin very darkbrown material "like mud." For the last six weeks he has llad much pain in the epigastrium and hypogastrium some ten minutes after food. Thrre has lately been no vomiting. The bowels have been loose, but without blood in the motions. $\mathrm{He}$ has suffered latterly from headaches and has grown thinner, and complains much of flatulence. On admission he was of good colour; the stomach was somewhat dilated and "splashed." There was no tumour, but the gastric region was tender in front. On washing out the stomach it was found to take $2 \frac{1}{2}$ pints of fluid and to require many washings before Condy's fluid came away unaltered ; but there was no blood or any offensive smell.

Here then was a clear histury of " coffee ground" vomit and tenderness probably pointing to gastric ulcer. The treatment has been careful dieting with digestible fluid food, and in washing out the residuum every day, together with the administration of bismuth carbonate. Under this he is improving, but is still tender, and the splashing in the stomach continues. If there was an ulcer it now shows but little evidence of its presence, and is presumably healing.

\section{Casir II.}

A young woman of 18 has for the last eight months or so suffered from the following symptoms and extreme anaemia. She has lived in Sussex, and has had the ordinary food of the labouring classes, but this has not agreed with her. She began eight months ago to suffer pain in the epigastrium soon after meals, with vomiting of all that was swallowed. There was never any blood in the matters brought up, but there was much bile. Two months ago her troubles became so acute that her friends became alarmed, and I was asked to give her an order for the medical out-patient department. Here she was treated by Dr. Risien Russell for chronic dyspepsia, with a suspicion of ga-tric ulcer. Returning home with the usual remedies and directions as to diet, she did not appear to improve, and I was told soon after that her symptoms were causing much alarm to her friends, as well as suffering to herself. I therefore admitted her here, and asked Dr. Russell to see her.

You must remember, gentlemen, that the salvation of these cases in the future will lie rather in their early medical treatment and dietary than in surgical interference later on. But the unfortunate aspect of the question is this, that there are multitudes of persons suffering from chronic dyspepsia in whom it is impossible to say positively whether there is an ulcer present in the stomach or not. And they are so very numerous that it is beyond our power to admit them all to hospital, and keep them long enough under observation to determine this very obscure point. Yet without this they are usually living under conditions most unfavourable for their cure, for all the medicines in the world will not benefit them if their diet and habits of life are unsuitable. This is why we get so many advanced cases with the most serious results as regards bleeding, cicatricial contraction, and perforation.

On admission this patient was most anaemic, almost chlorotic. She had pain and vomiting an hour or two after food, but without bleeding. This latter, if present, is signif- cant of gastric ulcer, but if absent does not negative the latter. Several of my cases in which I have operated for perforating ulcer of the stomach have never had any haematemesis from beginning to end. There was also tenderness in the epigastrium on the left side, but no dilatation. On washing out we found great gastric irritability, but the product did not show any marked change in the amount of nydrochloric acid. In brief we were left in doubt as to the actual change in the stomach walls, and could only suspect an ulcer from the irritability, pain, and tenderness.

The treatment has been the same as in Case r. Under it all the symptoms have greatly improved, and if there was an ulcer it has healed, or is healing. But we must keep this patient under treatment until we see that the stomach can digest painlessly such food as she is likely to get at home, and have trained her to diet herself properly. If this is not done she will relapse into her former condition, or perhaps worse, with all the dangers of haemorrhage, cicatricial contraction, or perforation

These are the three chief dangers from chronic ulceration. You have seen that haemorrhage was a feature in Case I, but not to any serious extent. In Case II it was absent, as indeed it is in many much more serious and even fatal cases. In neither were there any signs pointing to either contraction or perforation. Nevertheless, both had just the kind of trouble which, if neglected, terminates so often in either chronic disabling ill-health, or one or other of the dangerous complications mentioned.

\section{CASE III.}

This patient illustrates a more severe form of the same disease present for a much longer period, and productive of a much more alarming haemorrhage in spite of treatment both in and outside this hospital.

The patient, a domestic servant, gives a history of dyspepsia for many years. About three years ago this became aggravated, and she had vomiting of food with haematemesis. She improved after six months of treatment and went to work again. But about two years ago she suffered much in the same way, and brought up red blood. There was also pain between the shoulders and in the left hypochondriac region. Last June she was admitted into Dr. Roberts's ward with all these symptoms, and after a month of treatment was discharged relieved, She then went to Brighton, and returned to solid food, etc. She returned home in August, taking solids, but soon began to suffer with severe vomiting after meals and haematemesis. This lasted until December $30 t h, 1901$. She vomited nearly every day, and the pain was as before. With peptonised diet she has improved, but she states that a fortnight ago she brought up blood again. She was admitted on December 31 st anxious to obtain relief, if necessary by operation.

As you see, she looks fairly well and cheerful, and the abdomen looks normal. The only abnormality to be made out is great tenderness in the leit hypochondrium under the rectus muscle, and here there is much resistance. There is no dilatation, and washings came away clear (since tinged with blood, as also the vomit). In view of these symptoms and history, we may infer that she has a gastric ulcer in front inclining to bleed frequently, and probably contracting adhesions to the abdominal wall. As the treatment for now nearly three years has not cured her, and she runs considerable risks both from haemorrhage and perforation, it is necessary to consider the propriety of operating on the stomach either to remove the ulcerating portion or to make a gastroenterostomy to relieve the organ rapidly and regularly of ingesta and so help the ulcer to heal (see Note).

I will now relate another case of far more serious, indeed of actually fatal, haemorrhage from gastric ulcer. which some of you may have recently seen under my care in Ward 4 . It has many features of interest, but none greater than the difficulty it presented in diagnosing the actual condition of things in the stomach and in deciding what do so.

CASE IV.

M. R., aged 2I, a housemaid, was admitted under the care of Dr. Poore. Two years ago she had an attack of haematemesis, but soon recovered under careful dieting. On March 2nd, Igor, she again felt ill and had a bad headache. 'The next day she brought up two mouthfuls of blood in the after- 
uoon, and at Io P.M. half a besinful of blood. During all this time there was severe abdominal pain only partially relieved by the application of ice. On admission (March 6th) she was extremaly blunched but well nourished. The pulse was 124, the temperature $100.6^{\circ}$, and the respirations 20 . There was no distensiun or vomiting; bowels confined.

The pulse improved with nutrient enemata, and the next duy the fever fell to $99^{\circ}$, rising again on March 8th to $101.4^{\circ}$. A'ter this she was fed cautiously by the mouth with benefit. During the evening of March gth patient vomited about half a pint of bluod and became very restliess. The pulse also became weaker. Morphine was given and a pint of normal saline solution by the rectum. On the morning of March roth she became again very restless, and later the pain and tenderness in the epigastrium grew worse, but there was no distension. The liver dulness was lost along a strip about two or three inches from the edge of the sternum. The temperature was $1014^{\circ}$, and the pulse 130 ; abdomen motionless. Dr. Sidney Mrrtin now found an area of dullness at the base of the right lung and suspected diaphragmatic abscess. I was now asked tu see the patient and agreed to operate, as we supposed that a peifuration had taken place. On the operating table I found that the area of dullness over the right base was gone. On opening the abdomen we were uncertain as to the presence of gas. The stomach, which looked everywhere normal, was exumined front and back, but no evidence of perforation or bleeding into the organ could be found. The duodenum, too, was normal. There was no sign of peritonitis or of abscess uuder the diaphragm on either side, though carefully sought. The abdomen was closed; there was very little sho.k from the short operation. The blood was ver 7 watery. There was no change next day, except a rise of temperature to $102.4^{\circ}$, and later $103^{\circ}$. As there was again dullness over the right bave an aspirator needle was introduced, but nothing was found. Death occurred on March 12th at 4 P.M.

The post-mortem notes by the pathologist show no inflammation in the abdomen or chest. On opening the stomach nothing abuormal was found at first, and only after long search a piuhole opening into one of the vessels near the cardia was found to be the source of the haemorrhage. There was no other ulcer or abnormality on the inner or outer surface of thy stomach, even over the pinhole ulcer. After the stomach had beeu harilened the latter was seen to be surrounded by a shallow ero 1 inn of the mucous membrane the size of a sixpenny bit. This was probably the source of the infection which caused the fever.

I will now recall to your mind a case which you have seen which illustrates the danger of chronic intermittent haemorrhage frim an ulcer. And though the ulcer was probably in the upper part of the duodenum the moral is the same. Some of you will remember the operation and the return of the patient to show the excellent result.

\section{Case v.}

W. S., a railway clerk, was admitted on June 18th I901, from sympt ims of duodenal ulcer. He had been previuusly admitted in April, rgor, for the same trouble under Dr. Poore. six years ago he became ill, and in crossing the railway plutform fainted, and soon after passed motions like tar. In N.vveubrr, 1900, he had influenza, and again had tarry motions and great pain in the epigastrium two hours after food. In February, 1901, he had a relapse with much of the same pain, and passed blood for fourteen days. The pain was always in the epigastrium and localised to the midline. It always came on two hours after taking food. He has never vomited hlood. The appetite has been good, the bowels conrtipated.

On admission the patient complained of pain just below the ensifurm cartilage. He was very tender here, and slightly so all over the epigastrium to deep palpation. There was no tumour to be felt. The tongue showed the most perfectly marked "annulus migrans," changing daily in form. His weight wa\& 8 st. $9 \frac{1}{3}$ lbs., a great loss from his average. Otherwise he lo ked fairly well, but had been unable to do any work for s ven months, in spite of carefu! dieting.

Regurding the case as one of undoubted duodenal ulcer, and at the p-tient's urgent request, as well as that of his medical atteudunts at home, I performed retrocolic gastro-enterostomy on July 27th, 1901, to divert the food from the stomach directly into the jejunum, and so give the ulcer in the duodenum rest. There was very littleshock, but some regurgitation of brown fluid in small quantities troubled him on the second day ; on the third day this was relieved by siphoning off about 15 ounces of bl lody, bile-stained fluid in the morning, and again of $1 \frac{1}{2}$ ounce in the evening. Recovery was now perfect. The stitches were removed on the tenth day, and primary union was found. On July 21st, before operation, his weight had heen 8 st. $2 \frac{1}{2}$ lbs., on July 27 th 8 st. 8 lbs., and on leaving hospital 8 st. $10 \mathrm{lb}$. At the beginning of October you saw him here looking remarkably well, and weighing rost. He said he had lost all his trouble, could eat anything in reason, and was returning to work.

These last two cases furnish a good example of the dangers and disabilities of acute and chronic haemorrhage from gastric and duodenal ulcers, and we may now turn to two other recently treated here of cicatricial contraction; both were fortunately cured by operation. The first shows the condition in its simpler form, the second in one of its worst aspects.

Case vi.

Mrs. B., aged 56, first noticed heaviness after taking food early in the year 1901, and about February that she was losing flrsh and felt the cold more. These symptoms gradually increased, and palpitations were marked. There was great flatulence after food but never vomiting or melaena. In June she went to Dr. Clayton, of Belsize Park, who found a small tumour in the epigastrium, and at once dieted her. A week later no tumour could be found but at the end of June it was again present. The family history showed no trace of cancer. On armission, July 5th, rgor, the patient's weight was 8 st. 12 lbs., two years ago it was 10 st. 2 lbs. Two days after admission, in the same scales, her weight was 8 st. ro lbs. The stomach was washed out and a test meal given, the product being analysed by our pathologist. No gross abnormalities were found in it. Great relief was felt after washings. The abdomen was very flaccid and slightly distended. One inch above the navel in the middle line an irregular nodular tumour, the size of a small walnut, was evident. It varied in distinctness and hardness during manipulation. It moved freely up and down for $\frac{3}{4}$ inch, less easily laterally. The percussion note over it was resonant. The stomach was a little enlarged; the general condition was good. The diagnosis was pyloric ulcer and pyloritis with stenosis.

Operation (July 18th, 1901). - A median incision was made above the navel. On exposing the pylorus it felt hard, and $a$ little nodule the size of a pea was seen in it, of whitish colour, covered on its peritoneal aspect by a film of lymph. This nodule lay anteriorly in the pyloric ring, and a thickening extended from it all round the pylorus, so that the little finger invaginating the anterior wall of the stomach ( $H_{r h n}$ ) could not be passed through it. There were no enlarged glands in either omentum. Taking the condition to be one of pyloric ulcer and contraction, $I$ at once did $a$ typical retro-colic gastro-jejunostomy and closed the abdominal wound.

There was a good deal of pain in the area of operation on the second day, but otherwise nothing special to note. The stmmach tube was first passed on the third day, and a little bilious fuid was removed with relief. Recovery was perfect in ten days, when the stitches were removed. She went to the country on August 6th, within three weeks of operation. During October she presented herself at hospital for examination. She looked and felt very well, having lost all her old symptoms.

Let us now consider another far more serious case of cicatricial contraction from gastric ulcer which I have lately operated on here. You have since seen the patient in excellent health with a gain since operation of about 4 st. in weight.

Case vir.

E. H., aged 48, was admitted on July Ioth, I901, in a very feeble condition and only weighing 5 st. Io lbs., but suffering no pain. Abnve the navel was a perfectly healed scar from an operation by Mr. Stanley Boyd at Charing Cross Hospital just three weeks ago. There was no epigastric tenderness but some rigidity of the recti muscles which interfered with deep palpation. She had been sent to me by the kindness of Mr. Boyd when his hospital was closed. Six years ago the patient began 
to have symptoms of ga:tric ulcer with pain and haematemesis. Three years later another attack followed also with bleeding. In September, 1900, she first noticed a tumour in the epigastrium, which she states was larger when the pain was most severe. There was much pain and flatulence from time to time and marked loss of strength and weight.

\section{MR. BOYD'S NOTES.}

On admission to Charing Cross Hospital the patient was very thin and pale. The epigastriuin was sunken, and here a swelling about the size of a small orange coild be seen and felt; it was hard, smouth, moved with respiration, and was dull on percussion. The stomach was not dilated On June roth, roor, Mr. Bosd opened the abdomen in midline above the navel. In the wound and to the right of it lay a considerable tumour, involving the posterior surface and lesser curve of the stomach The anterior wall, abnormally red, seemed stretched over the mass The pylorus was free and normal. Two or three very obvious glands lay in the great omentum opposite the mass, and in the small omentum lay a low-lobed prominence springing from the thickened lesser curve. At first Mr. Boyd thought the tuinour malignant, but in the leit of the woind the stomach was densely adherent to the anterior abdominal wall and under surface of the liver over an area $1 \frac{1}{3}$ to 2 inches in diameter. This was obviously a simple matter. It encouraged the belief that the whole might be simple, and certainly accounted for a goou deal of pain. Separation of the stomach wis hardly begun before it was opened, the gap ultimately measuring three-quarters of an inch vertically. This was sutured in three layers with some difficulty, and the omentum was turned up and fixed to the lesser curve of the stomach so as to cover the sut ured wound and to lic between the stomach and the raw surface of the liver and abdominal wall from which it had been dissected. Mr. Boyd hoped thus to re-establish the mobility of the stomach.

Before the stomach wound was closed a finger was passed towards the pylorus, which ciuld yot be renched throngh the narrow chanuel about as long as the finger, and only just admitting it. The wall was smooth and hard, and did not bleed.

The patient recavered well, but continued to suffer much pain. Believing that the stomach tumour was possibly "simple" and a woman to Mr. Barker's care when Charing Cross Hospital closed.

With so clear a history I prepared the patient at once for operation in the usual way, and by injecting hypodermically twice a day half a litre of normal saline solution with 5 per cent. of pure glucose.

Operation (July I Ith, I90I). - The old scar was first opened np, and the opportnnity offered to me, by the courtesy of $\mathrm{Mr}$. Boyd, of seeing the condition of things within the abdomen produced by a gastrorrhaphy performed exactly three werks before was peculiarly interesting. Such opportunities will occur probably but rarely, and it is therefore of the greatest importance to note the effects of such an operation as accurately as po-sible while its results are fresh.

As there had been an extensive glueing of the anterior wall of the stomach to the back of the right rectus and liver. found and separated at the first operation, and as gastrorrhaphy involves considerable handling of the abdominal contents, I expected to find that many fresh adhesions had formed. But I was agreeably surprised to see that the latter were vory sparingly present. There were, to be sure, several bands running between the stomach and the abdominal wall, as well as others quite transparent uniting the organ with the liver and adjacent structures. But they were slender and those which it was necessary to divide gave no trouble from haemorrhage or otherwise. I was, of course, very careful not to put any strain upon the parts involved in Mr. Boyd's recent gastrorrlıphy, and, indeed, disturbed the anterior part of the organ as little as possible. The colon and omentum were theref(') at once turned up, and I performed a retrocolic gastro-j+junostomy in the usual manner. The stomach where [ reached its posterior surfaie appeared normal, but was contracted, and therefore hard to cont.ol and manipulate during suture. And when the anastomosis was finished I was much disturbed bo the appearance presented by the afferent and efferent arm of the liop attached to the stomach. They seemed murh to's parallel for a proper emptying of the stomach into the efferent armalone, and I was afraid of the formation of the well knon $n$ circulus vitiosus which has been fatal in so many cases. I ther'fore at once performed a second anastomosis betwern the ascending and dercending limb of the jejunal loop at about four inches in each from the point of anastomosis of the lonp with the stomach. This orcupied a further quarter of an hour, but when it was finished I felt much more easy about the result. The whole operation had taken an hour and ten minutes, and the patient's condition was gond at the end.

So far, in all the gastro-enterostomies which I have done, whether arute or retrocolic, I have seen no evidence of the vicious circle. But in this case it seemed probable that without the second anastomosis it would come into being; and I thought it better to forestall such a disaster, even at the cost of prolonging the operation, rather than run the risk of having to do a second one, perhaps a week or ten days after, when the patient's powers were even lower than on the table; where, indeed, they were generally low enough.

After the operation there was a good deal of pain and sickness, but the latter was relieved by washing out the stomach. $R+c o v e r y$ was rapid and uneventfal. The patient left hospital on August 28th with a weight of 7 st. I lhs., a gain of $19 \mathrm{lbs}$. in five weeks. When she returned in October some of you saw how well she looked, and how grateful she was for her relief after six years of suffering. Her weight was then taken here in the same scales, and was over 9 st.

The next two cases illustrate the great dangers of perforation. These may be met in some cases by an immediate operation, especially where the accident occurred while fasting, as in the first of the two. But in other cases no operation yet devised will save them when extravasation is wide-reaching, with one or more perforations, as in the second case.

L. F., aged 21, a housemaid, admitted March 7 th, rgor, had had good health until three years before. From this on pain after food and sickness were complained of occasionally. On March 7th she was walking upstairs before breakfast when she suddenly felt pain in the abdomen and sickness. She then lav down, and later was able for her work but not for food. The diagnosis of perforated ulcer of the stomach was made by Dr. Guy Hollings, of Endsleigh Gardens, and she was sent a short distance to our hospital at 7 P.M.

On admission the pulse was 120 and the temperature $100^{\circ}$. The general condition was good, the tongue clean, the abdomen slightly distended, not moving but tender above the navel. There was no tenderness of the skin. There was resonance in front and in the left flank and over the front of liver for two inchea above the costal margin. Axillary liver dulness was present.

Operation (March 7 th, 9 P.M.) -A median incision was made above the navel. The stomach was adherent to the abdominal wall by old and recent lymph. There was a perforation the size of sixpence on the anterior wall low down shut off from the general peritoneum by adhesions. The stomach wall around the perforation was too soft to hold sutures. Ultimately by including a good deal of tissue the wall was inverted and the opening closed with silk. Cleansing with gauze mops and drainage by the apron method were performed'as usual. The operation was well borne. The pulse fell from 160 to 112 aiter it, aided by our usual restoratives. For the first few days the patient's condition fluctuated, bu then began to improve, and at the end of three weeks, when $I$ went for a short holiday, seemed very satisfactory. Then the temperature was normal for two weeks or more. But on April 5 th, that is, 28 days after the operation, she died suddenly with symptoms of pulmonary embolism. Our pathologist's report runs as follows: "Perforated Gastric Ulcer: Operation Cure. Death from Pulmonary Embolism." As I was abroad at the time I asked for particulars and heard that all in the abdomen was satisfactory, but that the vagina was ulcerated, and the vaginal veins opening into iliac veins were thrombosed, and from this an embolism had broken off and lodged in the lungs.

Alice M., aged 28, admitted June 1st, 1901. There was a history of gastric ulcer for a long time. The patient was very f she ha I severe haematemesis, and had been in bed since. On May 3 oth she had sudden violent pain in the abdomen and all symptoms of perforation.

On admission on June ist, at 2 P.M., the pulse was I30, lips covert $d$ with sordes; the abdomen distended and motionless, hard, and tender to the right of the navel, and the liver dullness gone. I at once operated forty-five hours after perforation, evacuating a large quantity of glairy fluid from under the liver. The perforation was high up on the lesser curve, and was only closed with much difficulty. The abdo$m \cdot n$ WHS mopped out with gauze and drained with an apron. All efforts to maintain the patient's strength were in vain and she died eighteen hours after operation of shock and peritonitis. The necropsy showed that the latter was general, 
and that there was a long ulcer running across the lesser curvature, with a second perforation at its posterior end, which opened into the sac of the omentum.

\section{Conclusion.}

These 9 cases occurring before' you within a short interval offer a good deal of food for reflection. The first related were comparatively simple, and under careful treatment ought'tó recover without operation. But it is impossible to say in any case of gastric ulcer whether some of the severe complications will not arise, and when they may be dangerous. Some of the most terrible, such as haemorrhage, come "like a bolt from the blue," without any warning; others, such as cicatricial contraction, are preceded by a long train of troublesome symptoms. All this must make us reflect whether surgical treatment ought not to be employed in a far larger proportion of cases where proper medical measures are not leading to a cure; than is at present the case. Operation, as you have seen, is only a desperate last resource, where perforation or haemorrhage is surely killing a patient, whereas, as you have also seen, recovery from operations for the other nonmalignant conditions is the rule, if done before the patient is quite worn out.

So far, I am glad to say, all the operations I have done for non-malignant disease (without perforation) have been successful, and you have seen in some of the cases just related how completely they have relieved suffering and enabled the patients to blossom out into useful, active life again. The relief is perfectly marvellous often after years of suffering and inability to follow any avocation. I have recently had another in private, where a gentleman of 44 had been an invalid for a long time, and a great sufferer. A posterior gastro-jejunostomy has enabled him not; only to return to his hard work after only a fortnight in bed, but also to enjoy social life, from which he had long been cut off.

I could have emphasised these points by a much larger number of cases operated on, but have preferred to confine myself to those which you have had an opportunity of studying for yourselves quite recently.

\section{AN ADDRESS ON SOME POINTS IN CONNEXION WITH ULCERATION OF THE STOMACH AND DUODENUM.*}

Bx C. R. BOX, M.D.LoND.,

Assistant Physician, St. Thomas's Hospital : Assistant Physician, London Fever Hospital.

MY choice of ulceration of the stomach and duodenum as a subject on which to address you has been influenced by the great frequency with which such ulcerations occur; by the fact that the diagnosis of these ulcers is by no means so easy a matter as is commonly supposed; and by the serious complications which may occur in these affections, rendering their recognition and prompt treatment all-important.

It is impossible within the limits of a short paper to treat the subject of gastric and duodenal ułceration with exhaustive detail, so, with your permission, I propose to draw yourattention to a few points which appear to be of practical importance.

First, with regard to the probable causation of these ulcers. In the current textbooks on medicine one finds a bewildering number of theories with but little actual evidence to support them. The ulceration is variously ascribed to arterial thrombosis, to embolism, and to vascular obstruction caused either by endarteritis or by simple spasm, all leading presumably to the formation of an infarct or of a haemorrhagic area, which is in turn digested by the gastric juice. Mechanical injuries are also invoked, such as a continued pressure due to occupation, as in shoemakers, or the constant wearing of tight belts or corsets, or actual blows upon the epigastrium. Or, again, a diminished alkalinity or the blood is supposed to lower the power of resistance of the gastric wall, and so lead to its digestion.

* Rsad at a meeting of the South London District of the Metropolitan Branch of the British Medical Association.
Of late years one finds advocates of the theory of microbic infection of the lymphoid follicles of the stomach wall. This is certainly the mode of production to which I incline myself, and for the following reasons :

1. For any part of the intestinal tube below the duodenum the theory of the infective nature of ulceration is at once accepted. Typhoid, tuberculous, and dysenteric ulcerations are unanimously attributed to an infective cause. The same holds for ulcerative colitis and the destructive process in appendicitis.

2. The fact that it is not uncommon to find that ulcers both in the stomach and in the duodenum may be multiple, and not only multiple, but so placed-either exactly opposite or quite close to each other-that infection from one to the other may have easily occurred. When two uleers are placed. opposite to each other, it is said that close examination will often show that one is an older ulcer than the other. I have repeatedly met with these opposed ulcers post mortem, not only in the stomach but also in the duodenum.

3. The appearance of a recent acute ulcer at the time of operation for perforation is itself highly suggestive, and it was this appearance which first seriously directed my own attention to the microbic theory. Such an ulcer is always surrounded by a zone of highly ondematous and softened tissue of considerable extent. Stitches easily tear through the oedematous wall, and so considerable difficulty may be experienced in applying the sutures. Every surgeon who has had much experience of the suture of acute perforated ulcers recognises this oedematous condition.

Surrounding oedema is not present in every perforated ulcer, for there is a form of perforation which is conveniently termed "secondary" in contradistinction to the "primary" perforation of an acute ulcer.

By "secondary" perforation, we understand a perforation in the floor of an ulcer, due either to the rent of a thin peritoneal base, or the tearing of some old adhesions uniting such an ulcer to the surrounding structures. The perforation of a stomach in this way by disturbance of its adhesions or by tear of its peritoneal floor may be brought about by overdistension of the stomach by food, by taking copious draughts of fluid which weigh down the organ, or by some unwonted muscular exertion when the stomach is so distended.

An ulcer which has perforated in this manner, and not by active spread of an inflammatory process, need not present an area of surrounding oedema at all.

We must then somewhat modify our conceptions of the acute ulcer. Surrounding the round or oval and characteristically punched-out ulcer, containing, perhaps, a small necrotic slough, we must picture a large surrounding zone of oedema and softening, which can hardly be of other than inflammatory origin. Sometimes the recent ulcer so far departs from the textbook description that it actually has undermined edges like those of a recently-formed typhoid ulcer, an additional evidence of its formation by bacterial necrosis and sloughing.

What is true for the gastric ulcer, probably also holds for the common ulcer of the duodenum, nor do I believe it is necessary to assume that there is any essential difference in the origin of acute and chronic ulcers in these localities.

With regard to the embolic causation of gastric ulceration, the following points may be noted. It is difficult to produce ulceration this way experimentally; in those diseases in which embolisms of other viscera are most frequent, gastric ulceration is exceedingly rare; and when embolism of the stomach does take place, the embolus usually is produced by disease of one of the large arterial trunks in the neighbourhood of the stomach, such as, for instance, aneurysm of the coeliac axis. In the ordinary case of gastric ulcer one may search in vain for either the embolus or evidence of idisease such as might give rise to an embolic procese.

Superficial gastric ulceration is present in some cases of pyaemia, and gastric ulcer is sometimes met with in eases of mitral disease. In these cases the ulcers may possibly be of vascular origin.

The ordinary signs and symptoms of gastric and duodenal ulceration are too familiar to you to need any recapitulation on my part, so we may proceed at once to the consideration of two of the main signs, haematemesis and votniting. 